\title{
ОСНОВНЫЕ НАПРАВЛЕНИЯ УТИЛИЗАЦИИ УГЛЕПЛАСТИКОВ
}

СИльиных Г. В., ORCID: 0000-0002-8829-3500, SPIN-код: 2995-4576, канд. техн. наук, Пермский национальный исследовательский политехнический университет, г. Пермь, Россия, galina.perm.59@yandex.ru

\section{UTILIZATION OPTIONS FOR CARBON FIBER REINFORCED PLASTICS}

CIlinykh G., ORCID: 0000-0002-8829-3500, SPIN-code: 2995-4576, Ph.D., Perm National Research Polytechnic University,Perm, Russia, galina.perm.59@yandex.ru

Аннотация. В статье рассмотрены актуальные вопросы утилизации полимерных композиционных материалов на основе углеродного волокна (углепластиков). Особенности свойств углепластиков ограничивают возможности их утилизации с получением полезных вторичных продуктов. В качестве альтернативы захоронению углепластиков в настоящее время известны три основных направления их утилизации: термическая утилизация, основанная на термическом разложении матрицы, термохимическая утилизация, предполагающая одновременное воздействие температур и химических реагентов, а также механическая обработка, заключающаяся в дроблении, измельчении. У каждого направления есть свои преимущества и недостатки, свои ограничения и рекомендации, анализ которых представлен в статье.

Abstract. The article deals with important issues of utilization of polymer composite materials based on carbon fiber (CFRP). Properties of carbon fiber plastics limit possibilities of their utilization with reception of useful secondary products. As an alternative to CFRP disposal three main methods of their recycling are currently known: thermal treatment, based on the thermal decomposition of the polymer matrix, thermochemical treatment, involving simultaneous exposure to temperatures and chemicals, as well as mechanical processing, consisting in crushing and grinding. Each method has its advantages and disadvantages, its limitations and recommendations, the analysis of which is presented in the article.

Ключевые слова: полимерный композиционный материал, вторичное углеродное волокно, углепластик, утилизация, сжигание, пиролиз, сольволиз.

Keywords: polymer composite material, recycled carbon fiber, recycling, incineration, pyrolysis, solvolysis.

\section{Введение}

Композиционные материалы - это материалы, состоящие из двух или более компонентов, различающихся по своему составу и разделенных выраженной границей, свойства которых определяются свойствами каждого из компонентов. Такая двойственная природа композиционных материалов позволяет комбинировать желаемые свойства двух разных материалов и, тем самым, получать продукт, превосходящий по своим параметрам монокомпонентные аналоги. При этом с экологической точки зрения всякая комбинация 
нескольких материалов в одном изделии затрудняет дальнейшую утилизацию таких предметов после окончания их эксплуатации.

Полимерные композиционные материалы (ПКМ) на основе углеродного волокна (углепластики) благодаря своим исключительным физико-механическим свойствам, превосходящим традиционные материалы, например многие металлы и сплавы, находят применение при конструировании разнообразного высокотехнологичного оборудование в космической отрасли, авиа-и автомобилестроении и других направлениях. Однако в отличии металлов и сплавов, окончание жизненного цикла таких материалов связано с рядом экологических проблем. В то время как стали или алюминий - материалы, которые относительно легко перерабатываются, а лом черных и цветных металлов - востребованное вторичное сырье, обращение с отходами углепластиков достаточно новый вызов для отходоперерабатывающей промышленности, так как изготовление таких изделий началось относительно недавно, а объемы производства относительно невелики. С другой стороны, увеличение объемов производства в геометрической прогрессии приведет к тому, что масса ежегодно образующихся отходов станет критической и проблема потребует неотложного решения. Произойдет это даже раньше, чем пройдут десятилетия срока эксплуатации изделий из углепластиков длительного пользования, так как помимо отходов потребления при изготовлении изделий из углепластиков образуется большое количество отходов. В частности, при раскройке и выкладке будущих изделий до $30 \%$ препрегов уходит в отходы.

Поэтому уже сегодня активно выполняются исследования по разработке вариантов обращения с отходами углепластиков по окончании их жизненного цикла.

Особенностью углепластиков, как и большинства других композиционных конструкционных материалов, является невозможность их утилизации такими традиционными методами как, например, переплавка, широко используемая для металлов и многих полимеров (полиэтилена, полиэтилентерефталата и др.). Обычно в качества матрицы при производстве углепластиков используются реактопласты - неплавкие полимеры, разрушающиеся под действием температуры без образования расплава. Кроме того, углепластики производятся преимущественно с использованием непрерывных волокон или плетеных тканей, причем направление волокна имеет большое значение, так как углепластики - материалы с анизотропными свойствами. Соответственно, при утилизации отходов углепластиков, например, при термическом разрушении матрицы, полученное вторичное углеродное волокно будет дискретным и разнонаправленным.

В настоящее время известно и в определенной степени исследовано несколько основных направлений утилизации полимерных композиционных материалов (представлены на Рисунке).

Каждое из этих направлений имеет свою специфику, в том числе с точки зрения воздействия на окружающую среду. Захоронение относится к ликвидационным методам обращения с отходами углепластиков и не позволяет использовать ресурсный потенциал таких отходов. Сжигание в цементных печах позволяет полезно использовать энергетический потенциал отходов. Оставшиеся направления относятся к утилизационным методам обращения с отходами и позволяют получить тот или иной продукт для повторного использования. 


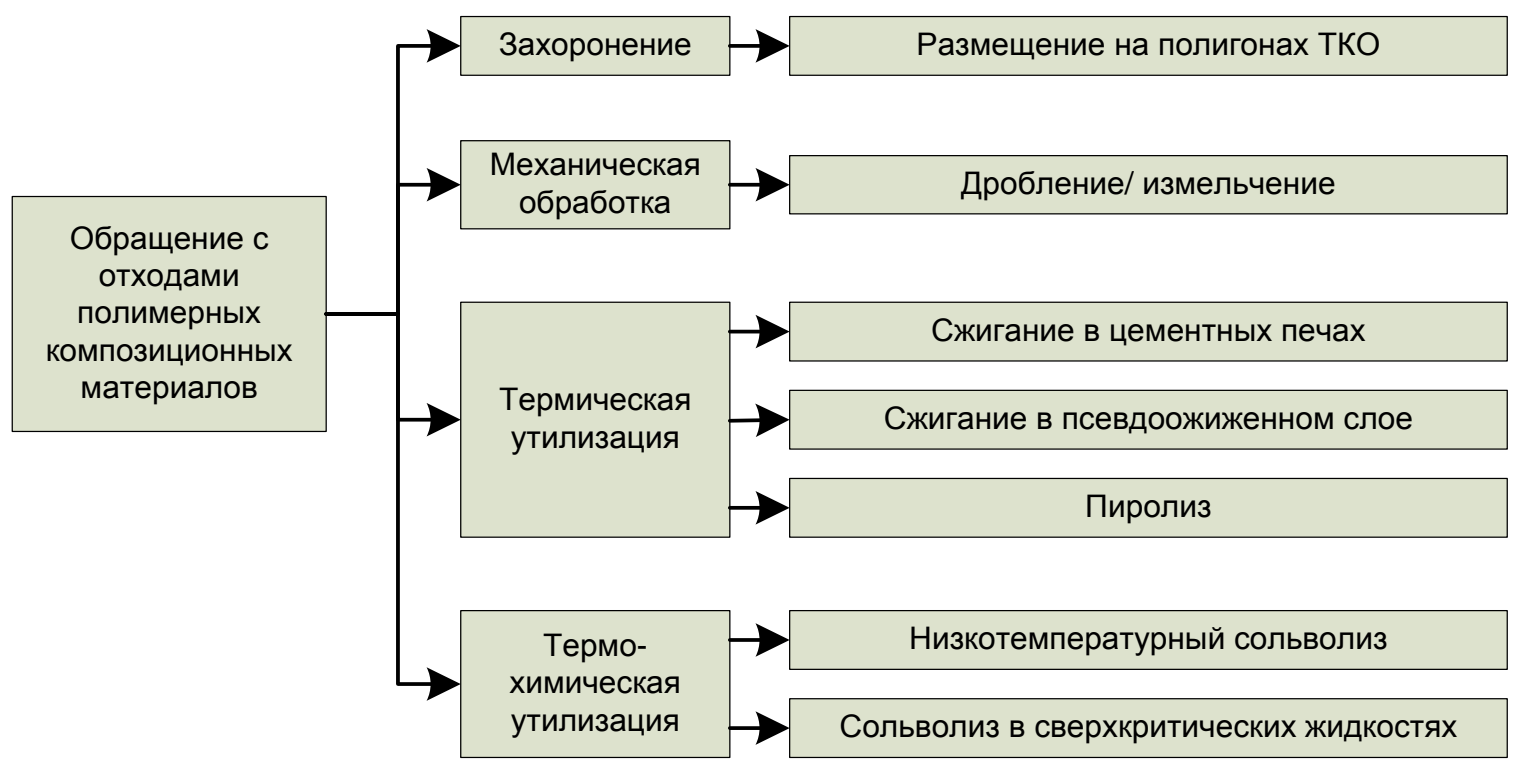

Рисунок. Основные направления утилизации углепластиков.

\section{Захоронение углепластиков (размещение на полигонах ТКО)}

Исторически сложилось так, что композитные компоненты от вышедших из эксплуатации самолетов и автомобилей выбрасывались на свалки. В настоящее время на смену несанкционированным и необорудованным свалкам приходят полигоны захоронения отходов - природоохранные сооружения, предназначенные для складирования ТБО и обеспечивающие защиту от загрязнения атмосферы, почв, подземных и поверхностных вод. Для этого полигоны оборудуются противофильтрационным экраном в основании, системами сбора и обезвреживания образующихся фильтрата и биогаза и другими устройствами. В сравнении со свалками полигоны обеспечивают значительное снижение негативного воздействия отходов на окружающую среду, однако связаны с определенными финансовыми затратами.

Хотя захоронение отходов даже на полигонах остается самым дешевым вариантом обращения с отходами композитов, в 2004 году большинство государств — членов Европейского союза (ЕC) приняли законы, запрещающие захоронение отходов, в том числе композитов [1]. В связи с этим, для композиционных материалов необходимо применять другие методы утилизации и обезвреживания. Введенный запрет подтолкнул производителей и потребителей углепластиков к поиску альтернативных решений проблемы.

В России в настоящее время применение углепластиков только начинается внедрятся в различные отрасли производства, поэтому объемы образования таких отходов незначительны (точная статистика отсутствует, однако по оценкам это не больше нескольких сотен тонн в год). Промышленно внедренные технологии их утилизации отсутствуют, отходы в полном объеме отправляются на захоронение.

\section{Механическая обработка (дробление, измельчение)}

Механическая обработка (измельчение) чаще всего рассматривается как способ утилизации стекловолокна, хотя отдельные исследования по применению этой технологии для углеродного волокна также имеются. Получаемое при этом углеродное волокно используется как наполнитель и как армирующий материал. Однако получение наполнителя из углеродных волокон экономически нецелесообразно, так как несравнимо более дешевые 
аналоги первичных материалов [2]. К недостаткам механической утилизации будут также относиться высокая энергоемкость, трудности в регулировании размеров полученного измельченного материала.

\section{Сжигание углепластиков в ијементных печах}

В соответствии с европейским законодательством сжигание ПКМ на основе стекловолокна в цементной печи считается в настоящее время оптимальным решением. ПКМ на основе углеродного волокна также подвергаются данному методу утилизации в отсутствии других альтернатив. Это более дорогой вариант в сравнении с захоронением, которое, однако, не везде разрешено [2].

\section{Сжигание углепластиков в псевдоожиженном слое}

Промышленно реализован еще один способ термического разложения смол и извлечения углеродного волокна - окисление в печах кипящего слоя. В процессе используется обычно кварцевый песок, псевдоожиженный горячим воздухом (поэтому условия являются окислительными). Это позволяет быстро нагревать материалы и освобождать волокна от смолы. Органическая фракция смолы утилизируется во вторичной камере сгорания при температуре около $1000{ }^{\circ} \mathrm{C}$ с возможностью получения энергии [2].

\section{Пиролиз углепластиков}

Среди термических методов наибольшее распространение и промышленное развитие получил пиролиз в отсутствии кислорода, с небольшим количеством кислорода или в присутствии пара. Условия пиролиза относительно одинаковы для разных технологий. Температура процесса пиролиза обусловлена оптимальными условиями разложение матрицы и составляет обычно $500^{\circ} \mathrm{C}$ до $550^{\circ} \mathrm{C}$, что позволяет с одной стороны максимально сохранить механические свойства углеродного волокна, а с другой стороны обеспечить максимальное разложение полимерных компонентов и освобождение волокна. Присутствие небольшого количества кислорода требуется для минимизации образования на поверхности вторичного углеродного волокна пироуглерода, который ухудшает адгезию волокна к новой матрице при вторичном использовании [2].

Помимо обычного пиролиза в качестве возможных технологий утилизации ПКМ предлагается пиролиз с обработкой микроволнами Основным преимуществом микроволн является то, что материал нагревается в своей сердцевине, что обеспечивает очень быстрый перенос тепла, что позволяет минимизировать тепловые потери в окружающую среду и экономить энергию. Микроволновый пиролиз нагревает отходы ПКМ в инертной атмосфере, разлагая матрицу на газы и маслянистый остаток [2].

\section{Низкотемпературный сольволиз углепластиков}

Основное преимущество низкотемпературного сольволиза по сравнению с пиролизом состоит в том, что для разложения полимеров, в частности эпоксидных смол, обычно необходимы более низкие температуры. Низкотемпературный сольволиз обычно проводят при температуре ниже $200^{\circ} \mathrm{C}$ и при атмосферном давлении. Так как температура процесса достаточно низкая для разложения смолы необходимы катализаторы, реагенты и перемешивание. При низкотемпературном пиролизе обычно используется кислая среда (азотная, серная и уксусная кислоты) по сравнению с высокотемпературным пиролизом, где обычно используются щелочные условия. Некоторые кислотные растворы очень едкие и могут быть очень опасными для здоровья населения и окружающей среды. Преимущество 
низкотемпературного сольволиза в том, что он обеспечивает лучший контроль за происходящими реакциями и может использоваться для ПКМ, которые невозможно утилизировать другими методами [2].

Условия низкотемпературного сольволиза гораздо разнообразнее, чем условия пиролиза, ввиду многообразия реагентов и их комбинаций.

Исследователями [3] предложен метод извлечения углеродного волокна обработкой смесью разбавленной азотной кислоты и перекиси водорода в присутствии ультразвука. Максимальная степень разложения смолы 95\% может быть получена для эпоксидной матрицы. При этом отсутствует потребность в сильных химикатах и высоких температурах и давлениях.

Возможна химическая обработка при атмосферном давлении - по данным исследования [4] деполимеризация (бензиловый спирт/фосфат калия при $200^{0} \mathrm{C}$ ) и обработка горячей кислотой (уксусная кислота/перекись водорода при $110^{0} \mathrm{C}$ ) были эффективны для растворения отвержденной амином чистой эпоксидной смолы. Результаты показали, что кислотное расщепление более эффективно для сильно сшитых амин/эпоксидных композитов, чем деполимеризация. Кроме того, расщепление происходило посредством стадий реакции переноса атома кислорода к анилиновым группам и затем расщепления связи, что приводило к извлечению волокон практически чистого качества при более высоких скоростях растворения и более низких температурах. Основным фактором, ограничивающим скорость переваривания кислоты, была скорость диффузии, а не скорость химической реакции. Были оценены две стратегии повышения скорости диффузии - предварительная обработка и механическое измельчение, и обе были эффективными - полимерные матрицы в предварительно обработанных и измельченных композитах были гомогенно разложены в течение 1 часа.

Извлечение углеродного волокна возможно при обработке ПКМ перуксусной кислотой, образующейся в растворе из смеси уксусной кислоты и пероксида водорода. Исследователями [5] предложен возможный механизм реакции разрушения эпоксидной матрицы. Все используемые растворители были извлечены в чистом виде и пригодны для повторного использования с эффективностью восстановления более 90\%. Практически полное извлечение переработанных продуктов, а также растворителя при отсутствии газообразных выбросов и мягкие условия реакции делают этот процесс более экологичным.

Двухэтапный метод извлечения углеродных волокон из композитов с эпоксидной смолой в мягких условиях включал в себя два этапа [6]. Чтобы получить большую площадь поверхности композиты были обработаны в уксусной кислоте, при этом ПКМ становятся разбухшими и слоистыми. Затем в герметичном реакторе ПКМ обрабатываются раствором перекиси водорода и $\mathrm{N}, \mathrm{N}$-диметилформамида в течение 30 минут. Полученный при этом коэффициент разложения эпоксидной смолы в композитах был более $90 \%$, а прочность на растяжение углеродных волокон составила более 95\% от исходных параметров по данным испытаний на растяжение одиночного волокна.

Эффективная стратегия разложения эпоксидной смолы ПКМ включает использование хлорида алюминия и уксусной кислоты в качестве системы разложения [7]. Уксусная кислота приводит к набуханию смолы и проникновению иона алюминия (катализатора) в полимерную матрицу. Ионы алюминия в растворе уксусной кислоты селективно расщепляют связь $\mathrm{C}-\mathrm{N}$, оставляя связи $\mathrm{C}-\mathrm{C}, \mathrm{C}-\mathrm{O}$ нетронутыми. Этот процесс позволяет получать ценные олигомеры и углеродные волокна. 
Окислительное разложение эпоксидной смолы возможно в мягких условиях с ацетоном и перекисью водорода [8]. Степень разложения эпоксидной смолы превышает $90 \%$, а прочность углеродного волокна составляет более $95 \%$ от первоначальной.

Система полиэтиленгликоль/гидроксид натрия использовалась для химической переработки композитов с эпоксидной смолой [9]. После реакции при атмосферном давлении в течение 4 ч при $200^{\circ} \mathrm{C}$ с 0,1 г NaOH/г композита была получена эффективность разложения смолы на уровне 84,1-93,0\%.

Возможность многократного использована ацетона в качестве растворителя для разложения эпоксидной смолы для снижения его расхода была исследована [10]. Было обнаружено, что рециркулируемый растворитель становится все более концентрированным с продуктами разложения эпоксидной смолы. Эти продукты разложения способствуют и усиливают разложение композита.

Известны технологии сольволиза с дополнительной обработкой микроволнами, которые позволяют интенсифицировать процесс.

\section{Сольволиз углепластиков в сверхкритических жидкостях}

Высокотемпературный сольволиз с использованием сверхкритических жидкостей рассматривается как перспективный метод извлечения углеродного волокна хорошего качества. Для создания сверхкритических условий, например, для воды, нужны специальные дорогостоящие реакторы, которые должны выдерживать высокие температуры и давления, а также коррозию из-за измененных свойств растворителей. Помимо воды для сольволиза применяются растворы спиртов, фенолов, аминов [2].

В исследовании [11] использовалась сверхкритическая вода без добавления растворителей и было достигнуто удаление 99,9\% эпоксидных смол. Условия проведения процесса: температура $405 \pm 2{ }^{\circ} \mathrm{C}$, давление $280 \pm 10$ бар.

Деградация до 98\% эпоксидной смолы была достигнута при обработке ПКМ с использованием смеси ацетона и воды при температуре $320^{\circ} \mathrm{C}$ (сверхкритические условия) [12]. Увеличение времени обработки с 1 до 2 часов показывает увеличение степени разложения всего на 10\%, поэтому в дальнейшем продолжении процесса нет смысла. Измельчение образца перед обработкой также не оказывает существенного влияния.

Возможно использование воды в условиях, близких к критическим, в реакторе периодического действия (1 л) при температурах и давлениях до $350{ }^{\circ} \mathrm{C}$ и давлении 170 бар [13]. В образцах жидкой фазы удалось идентифицировать различные фенольные и ароматические соединения. В образцах, собранных при разложении полиэфирных композитов, мономер фталевой кислоты выпадал в осадок практически очищенным при температурах в диапазоне $250-325^{\circ} \mathrm{C}$.

\section{Общзая характеристика технологий}

Характеристика рассмотренных технологий с точки зрения потребляемых ресурсов (воды, электроэнергии и др.) и получаемых продуктов волокна, олигомеров и др.) представлена в Таблице.

Утилизационные технологии сжигания в печах кипящего слоя, пиролиза и сольволиза позволяют получать вторичное углеродное волокно для повторного использования. От технологии извлечения зависит качество получаемого волокна, в первую очередь механические свойства и возможные области применения. 

КОМПОЗИЦИОННЫХ МАТЕРИАЛОВ НА ОСНОВЕ УГЛЕРОДНОГО ВОЛОКНА [14-15]

\begin{tabular}{|c|c|c|c|c|c|c|c|}
\hline \multirow{3}{*}{ Мemod } & \multicolumn{7}{|c|}{ Расход/приход на 1 кг ПКМ на основе углеродного волокна* } \\
\hline & \multicolumn{2}{|c|}{$\begin{array}{c}\text { Затрачиваемые } \\
\text { ресурсы }\end{array}$} & \multicolumn{5}{|c|}{ Получаемые продукты } \\
\hline & $\begin{array}{l}\text { Энергии / } \\
\text { топлива }\end{array}$ & $\begin{array}{l}\text { материа- } \\
\text { лов }\end{array}$ & $\begin{array}{l}\text { энер- } \\
\text { гия }\end{array}$ & $\begin{array}{c}\text { полезны } \\
\text { материа- } \\
\text { лы }\end{array}$ & $\begin{array}{c}\text { продукты } \\
\text { заменяемые } \\
\text { ресурсы }\end{array}$ & $\begin{array}{c}\text { выбро- } \\
\text { сыb }\end{array}$ & отходы \\
\hline Захоронение & - & - & - & - & - & - & 1 кг ПКМ \\
\hline $\begin{array}{l}\text { Дробление / } \\
\text { измельчение }\end{array}$ & $\begin{array}{l}0,075 \\
\mathrm{KBT}^{*} \mathrm{\Psi}\end{array}$ & - & - & $\begin{array}{l}0,79 \text { кг } \\
\text { фибры } \\
0,21 \text { кг } \\
\text { порошка } \\
\end{array}$ & $\begin{array}{l}\text { стеклово- } \\
\text { локно } \\
\text { наполни- } \\
\text { тели } \\
\end{array}$ & - & - \\
\hline $\begin{array}{l}\text { Сжигание в } \\
\text { цементных } \\
\text { печах }\end{array}$ & - & - & $\begin{array}{l}32 \\
\text { МДж }\end{array}$ & $\begin{array}{l}0,08 \text { кг (в } \\
\text { клинкере) }\end{array}$ & сырье & $\begin{array}{l}3,36 \text { кг } \\
\mathrm{CO}_{2}\end{array}$ & - \\
\hline $\begin{array}{l}\text { Сжигание в } \\
\text { псевдоожи- } \\
\text { женном слое }\end{array}$ & $\begin{array}{l}\begin{array}{l}0,95 \\
\text { кВт*ч }\end{array} \\
1,1 \text { МДж } \\
\text { прир. газа }\end{array}$ & - & - & $\begin{array}{l}0,55 \text { кг } \\
\text { волокна }\end{array}$ & $\begin{array}{l}\text { первичное } \\
\text { углеволокно }\end{array}$ & $\begin{array}{l}0,9 \text { кг } \\
\mathrm{CO}_{2} \\
0,23 \text { кг } \\
\text { воды }\end{array}$ & - \\
\hline Пиролиз & $\begin{array}{l}8,33 \\
\mathrm{KBT}^{*} \mathrm{u}\end{array}$ & - & - & $\begin{array}{l}0,55 \text { кг } \\
\text { волокна } \\
0,28 \text { кг } \\
\text { горючих } \\
\text { продуктов }\end{array}$ & $\begin{array}{l}\text { первичное } \\
\text { углеволокно } \\
\text { топливо }\end{array}$ & $\begin{array}{l}0,9 \text { кг } \\
\mathrm{CO}_{2}\end{array}$ & - \\
\hline $\begin{array}{l}\text { Низкотемпера- } \\
\text { турный } \\
\text { сольволиз }\end{array}$ & $\begin{array}{l}1,81 \\
\mathrm{KBT}^{*}{ }_{\mathrm{Y}}\end{array}$ & $\begin{array}{l}0,45 \text { кг } \\
\text { уксусной } \\
\text { к-ты } \\
0,04 \text { кг } \\
\mathrm{NaOH} \\
1,65 \text { кг } \\
\text { воды }\end{array}$ & - & $\begin{array}{l}\begin{array}{l}0,55 \text { кг } \\
\text { волокна }\end{array} \\
0,35 \text { кг } \\
\text { олигомеро } \\
\text { в }\end{array}$ & $\begin{array}{l}\text { первичное } \\
\text { углеволокно } \\
\text { смолы?** }\end{array}$ & - & $\begin{array}{l}\text { отработан- } \\
\text { ный } \\
\text { сольволиз- } \\
\text { ный } \\
\text { раствор?** }\end{array}$ \\
\hline $\begin{array}{l}\text { Сольволиз с } \\
\text { микроволно- } \\
\text { вым } \\
\text { воздействием }\end{array}$ & $\begin{array}{l}2,78 \\
\text { кВт } *_{ч}\end{array}$ & & - & $\begin{array}{l}0,65 \text { кг } \\
\text { волокна } \\
0,19 \text { кг } \\
\text { олигомеро } \\
\text { в } \\
\end{array}$ & $\begin{array}{l}\text { первичное } \\
\text { углеволокно } \\
\text { смолы?** }\end{array}$ & - & $\begin{array}{l}\text { отработан- } \\
\text { ный } \\
\text { сольволиз- } \\
\text { ный } \\
\text { раствор?** }\end{array}$ \\
\hline $\begin{array}{l}\text { Сольволиз в } \\
\text { сверхкритичес- }\end{array}$ & $\begin{array}{l}2,61 \\
\kappa B T^{*} \mathrm{u}\end{array}$ & $\begin{array}{l}3,5 \text { кг } \\
\text { воды }\end{array}$ & - & $\begin{array}{l}0,65 \text { кг } \\
\text { волокна } \\
\end{array}$ & $\begin{array}{l}\text { первичное } \\
\text { углеволокно }\end{array}$ & - & $\begin{array}{l}\text { отработанн } \\
\text { ый }\end{array}$ \\
\hline ких жидкостях & $\begin{array}{c}1,64 \text { м }^{3} \\
\text { прир. газа }\end{array}$ & $\begin{array}{c}72 \text { т воды } \\
\text { (охлажден } \\
\text { ие) }\end{array}$ & & $\begin{array}{c}0,35 \text { кг } \\
\text { олигомеро } \\
\text { в }\end{array}$ & смолы?** & & $\begin{array}{l}\text { сольволизн } \\
\text { ый } \\
\text { раствор?** }\end{array}$ \\
\hline
\end{tabular}

*Учтены только значительные или маркерные потоки для базовых вариантов реализации методов;

**Полезное использование получаемых смол ограничено, поэтому их в разных случаях можно рассматривать и как ресурс и как отходы.

\section{Bblвodbl}

Для утилизации отходов углепластиков используются термические, термохимические и механические методы. При извлечении углеродного волокна термическими методами происходит разложение и последующее сжигание продуктов разложения органической полимерной матрицы, однако при правильно подобранной температуре возможно получение достаточно качественного волокна. Наличие небольшого количества кислорода в среде, в 
которой происходит термическая утилизация, кроме того, позволяет максимально избавиться от остатков смолы и пироуглерода. Для термохической утилизации отходов углепластиков используются более мягкие температурные условия, которые, однако, дополняются различными, иногда достаточно агрессивными, реагентами. В итого это позволяет более гибко управлять качеством получаемого вторичного волокна, однако компоненты матрицы, перешедшие в виде мономеров и олигомеров в раствор, не всегда могут быть полезно использованы ввиду их качества, поэтому утилизация таких растворов может стать проблемой. Механические методы с учетом характеристик и стоимости получаемых вторичных продуктов не могут рассматриваться как практически применимые методы утилизации.

Результаты, представленные в статье, были получены в ходе выполнения государственного задания Министерства образования и науки РФ в рамках мероприятия «Инициативные научные проектыл», код заявки 5.9729.2017/8.9.

\section{Список литературы:}

1. Rush S. Carbon fiber: life beyond the landfil // High-Performance Composites. 2007. Vol. 15. №3. P. 52-55.

2. Oliveux G., Dandy L. O., Leeke G. A. Current status of recycling of fibre reinforced polymers: Review of technologies, reuse and resulting properties // Progress in Materials Science. 2015. Vol. 72. P. 61-99. https://doi.org/10.1016/j.pmatsci.2015.01.004

3. Das M., Varughese S. A novel sonochemical approach for enhanced recovery of carbon fiber from CFRP waste using mild acid-peroxide mixture // ACS Sustainable Chemistry \& Engineering. 2016. Vol. 4. №4. P. 2080-2087. https://doi.org/10.1021/acssuschemeng.5b01497

4. Ma Y., Nutt S. Chemical treatment for recycling of amine/epoxy composites at atmospheric pressure // Polymer degradation and stability. 2018. Vol. 153. P. 307-317. https://doi.org/10.1016/j.polymdegradstab.2018.05.011

5. Das M., Chacko R., Varughese S. An Efficient Method of Recycling of CFRP Waste Using Peracetic Acid // ACS Sustainable Chemistry \& Engineering. 2018. Vol. 6. №2. P. 1564-1571. https://doi.org/10.1021/acssuschemeng.7b01456

6. Xu P., Li J., Ding J. Chemical recycling of carbon fibre/epoxy composites in a mixed solution of peroxide hydrogen and $\mathrm{N}, \mathrm{N}$-dimethylformamide // Composites Science and Technology. 2013. Vol. 82. P. 54-59. https://doi.org/10.1016/j.compscitech.2013.04.002

7. Wang Y., Cui X., Ge H., Yang Y., Wang Y., Zhang C., ... Hou X. Chemical recycling of carbon fiber reinforced epoxy resin composites via selective cleavage of the carbon-nitrogen bond // ACS Sustainable Chemistry \& Engineering. 2015. Vol. 3. №12. P. 3332-3337. https://doi.org/10.1021/acssuschemeng.5b00949

8. Li J., Xu P. L., Zhu Y. K., Ding J. P., Xue L. X., Wang Y. Z. A promising strategy for chemical recycling of carbon fiber/thermoset composites: self-accelerating decomposition in a mild oxidative system // Green Chemistry. 2012. Vol. 14. №12. P. 3260-3263. https://doi.org/10.1039/C2GC36294E

9. Yang P., Zhou Q., Li X. Y., Yang K. K., Wang Y. Z. Chemical recycling of fiber-reinforced epoxy resin using a polyethylene glycol/ $\mathrm{NaOH}$ system // Journal of Reinforced Plastics and Composites. 2014. Vol. 33. №22. P. 2106-2114. https://doi.org/10.1177\%2F0731684414555745

10. Sokoli H. U., Simonsen M. E., Søgaard E. G. Investigation of degradation products produced by recycling the solvent during chemical degradation of fiber-reinforced composites // 
Journal of Reinforced Plastics and Composites. 2017. Vol. 36. №17. P. 1286-1296. https://doi.org/10.1177\%2F0731684417707060

11. Kim Y. N., Kim Y. O., Kim S. Y., Park M., Yang B., Kim J., Jung Y. C. Application of supercritical water for green recycling of epoxy-based carbon fiber reinforced plastic // Composites $\begin{array}{llllll}\text { Science } \quad \text { and } & \text { Technology. } & 2019 . & \text { Vol. } & 173 . & \text { P. }\end{array}$ https://doi.org/10.1016/j.compscitech.2019.01.026

12. Keith M. J., Oliveux G., Leeke G. A. Optimisation of solvolysis for recycling carbon fibre reinforced composites. 2016. http://dspace.lib.cranfield.ac.uk/handle/1826/10334

13. Sokoli H. U., Simonsen M. E., Nielsen R. P., Henriksen J., Madsen M. L., Pedersen N. H., Søgaard E. G. Characterization of the liquid products from hydrolyzed epoxy and polyester resin composites using solid-phase microextraction and recovery of the monomer phthalic acid // Industrial \& Engineering Chemistry Research. 2016. Vol. 55. №34. P. 9118-9128. https://doi.org/10.1021/acs.iecr.6b02111

14. Meng F., Olivetti E. A., Zhao Y., Chang J. C., Pickering S. J., McKechnie J. Comparing life cycle energy and global warming potential of carbon fiber composite recycling technologies and waste management options // ACS Sustainable Chemistry \& Engineering. 2018. Vol. 6. №8. P. 9854-9865. https://doi.org/10.1021/acssuschemeng.8b01026

15. Dong P. A. V., Azzaro-Pantel C., Cadene A. L. Economic and environmental assessment of recovery and disposal pathways for CFRP waste management // Resources, Conservation and Recycling. 2018. Vol. 133. P. 63-75. https://doi.org/10.1016/j.resconrec.2018.01.024

\section{References:}

1. Rush, S. (2007). Carbon fiber: life beyond the landfil. High-Performance Composites, 15(3), 52-55.

2. Oliveux, G., Dandy, L. O., \& Leeke, G. A. (2015). Current status of recycling of fibre reinforced polymers: Review of technologies, reuse and resulting properties. Progress in Materials Science, 72, 61-99. https://doi.org/10.1016/j.pmatsci.2015.01.004

3. Das, M., \& Varughese, S. (2016). A novel sonochemical approach for enhanced recovery of carbon fiber from CFRP waste using mild acid-peroxide mixture. ACS Sustainable Chemistry \& Engineering, 4(4), 2080-2087. https://doi.org/10.1021/acssuschemeng.5b01497

4. Ma, Y., \& Nutt, S. (2018). Chemical treatment for recycling of amine/epoxy composites at atmospheric pressure. Polymer degradation and stability, 153, 307-317. https://doi.org/10.1016/j.polymdegradstab.2018.05.011

5. Das, M., Chacko, R., \& Varughese, S. (2018). An Efficient Method of Recycling of CFRP Waste Using Peracetic Acid. ACS Sustainable Chemistry \& Engineering, 6(2), 1564-1571. https://doi.org/10.1021/acssuschemeng.7b01456

6. Xu, P., Li, J., \& Ding, J. (2013). Chemical recycling of carbon fibre/epoxy composites in a mixed solution of peroxide hydrogen and N, N-dimethylformamide. Composites Science and Technology, 82, 54-59. https://doi.org/10.1016/j.compscitech.2013.04.002

7. Wang, Y., Cui, X., Ge, H., Yang, Y., Wang, Y., Zhang, C., ... \& Hou, X. (2015). Chemical recycling of carbon fiber reinforced epoxy resin composites via selective cleavage of the carbonnitrogen bond. ACS Sustainable Chemistry \& Engineering, 3(12), 3332-3337. https://doi.org/10.1021/acssuschemeng.5b00949

8. Li, J., Xu, P. L., Zhu, Y. K., Ding, J. P., Xue, L. X., \& Wang, Y. Z. (2012). A promising strategy for chemical recycling of carbon fiber/thermoset composites: self-accelerating decomposition in a mild oxidative system. Green Chemistry, 14(12), 3260-3263. https://doi.org/10.1039/C2GC36294E 
9. Yang, P., Zhou, Q., Li, X. Y., Yang, K. K., \& Wang, Y. Z. (2014). Chemical recycling of fiber-reinforced epoxy resin using a polyethylene glycol/ $\mathrm{NaOH}$ system. Journal of Reinforced Plastics and Composites, 33(22), 2106-2114. https://doi.org/10.1177\%2F0731684414555745

10. Sokoli, H. U., Simonsen, M. E., \& Søgaard, E. G. (2017). Investigation of degradation products produced by recycling the solvent during chemical degradation of fiber-reinforced composites. Journal of Reinforced Plastics and Composites, 36(17), 1286-1296. https://doi.org/10.1177\%2F0731684417707060

11. Kim, Y. N., Kim, Y. O., Kim, S. Y., Park, M., Yang, B., Kim, J., \& Jung, Y. C. (2019). Application of supercritical water for green recycling of epoxy-based carbon fiber reinforced $\begin{array}{lllll}\text { plastic. Composites } \quad \text { Science } & \text { Technology, } & \text { 173, } & \text { 66-72. }\end{array}$ https://doi.org/10.1016/j.compscitech.2019.01.026

12. Keith, M. J., Oliveux, G., \& Leeke, G. A. (2016). Optimisation of solvolysis for recycling carbon fibre reinforced composites. http://dspace.lib.cranfield.ac.uk/handle/1826/10334

13. Sokoli, H. U., Simonsen, M. E., Nielsen, R. P., Henriksen, J., Madsen, M. L., Pedersen, N. H., \& Søgaard, E. G. (2016). Characterization of the liquid products from hydrolyzed epoxy and polyester resin composites using solid-phase microextraction and recovery of the monomer phthalic acid. Industrial \& Engineering Chemistry Research, 55(34), 9118-9128. https://doi.org/10.1021/acs.iecr.6b02111

14. Meng, F., Olivetti, E. A., Zhao, Y., Chang, J. C., Pickering, S. J., \& McKechnie, J. (2018). Comparing life cycle energy and global warming potential of carbon fiber composite recycling technologies and waste management options. ACS Sustainable Chemistry \& Engineering, 6(8), 9854-9865. https://doi.org/10.1021/acssuschemeng.8b01026

15. Dong, P. A. V., Azzaro-Pantel, C., \& Cadene, A. L. (2018). Economic and environmental assessment of recovery and disposal pathways for CFRP waste management. Resources, Conservation and Recycling, 133, 63-75. https://doi.org/10.1016/j.resconrec.2018.01.024

Работа поступила

в редакииюю 14.11.2019 2.
Принята к публикациии 19.11.2019 2.

Ссылка для цуитирования:

Ильиных Г. В. Основные направления утилизации углепластиков // Бюллетень науки и практики. 2019. Т. 5. №12. С. 69-78. https://doi.org/10.33619/2414-2948/49/08

Cite as (APA):

Ilinykh, G. (2019). Utilization Options for Carbon Fiber Reinforced Plastics. Bulletin of Science and Practice, 5(12), 69-78. https://doi.org/10.33619/2414-2948/49/08 (in Russian). 